\title{
Preparation of Mesoporous SBA-16 Silica-Supported Biscinchona Alkaloid Ligand for the Asymmetric Dihydroxylation of Olefins
}

\author{
Shaheen M. Sarkar, ${ }^{1}$ Md. Eaqub Ali, ${ }^{2}$ Md. Lutfor Rahman, ${ }^{1}$ and Mashitah Mohd Yusoff ${ }^{1}$ \\ ${ }^{1}$ Faculty of Industrial Sciences and Technology, University Malaysia Pahang, 26300 Gambang, Kuantan, Malaysia \\ ${ }^{2}$ Nanotechnology and Catalysis Research Centre (NanoCat), University of Malaya, Level 3, Block A, IPS Building, \\ 50603 Kuala Lumpur, Malaysia
}

Correspondence should be addressed to Md. Eaqub Ali; eaqubali@gmail.com

Received 21 March 2014; Revised 20 May 2014; Accepted 21 May 2014; Published 15 June 2014

Academic Editor: Daniela Predoi

Copyright (C) 2014 Shaheen M. Sarkar et al. This is an open access article distributed under the Creative Commons Attribution License, which permits unrestricted use, distribution, and reproduction in any medium, provided the original work is properly cited.

Optically active cinchona alkaloid was anchored onto mesoporous SBA-16 silica and the as-prepared complex was used as a heterogeneous chiral ligand of osmium tetraoxide for the asymmetric dihydroxylation of olefins. The prepared catalytic system provided $90-93 \%$ yield of vicinal diol with $92-99 \%$ enantioselectivity. The ordered mesoporous SBA-16 silica was found to be a valuable support for the cinchona alkaloid liganded osmium catalyst system which is frequently used in chemical industries and research laboratories for olefin functionalization.

\section{Introduction}

The discovery of highly ordered mesoporous materials has opened up new fields of research in advanced chemistry, modern electronics, and nanotechnology [1-3]. Ordered mesoporous SBA-16 is a nanostructured porous material with a $3 \mathrm{D}$ cubic arrangement of mesopores that corresponds to the $\operatorname{Im} 3 m$ space group [4-9]. The surface properties of such materials could be significantly modified by adding organic groups and various functionalities onto them [10]. Our interest in the field led us to prepare SBA-16 silicasupported biscinchona alkaloid for osmium-catalyzed asymmetric dihydroxylation (AD) of olefins. Osmium-catalyzed asymmetric dihydroxylation of olefins is an attractive method for the synthesis of optically active diols [11-14]. Cinchona alkaloid-based osmium complexes are harmless and known to be the most effective chiral catalysts for $\mathrm{AD}$ reactions in terms of both reactivity and enantioselectivity [15-18].

However, the high cost and toxicity of osmium are a serious concern and many efforts have been devoted to overcome the issue including the development of heterogeneous catalyst ligand to trap the osmium $[19,20]$. Immobilization of homogeneous catalysts onto various supports has emerged as a major route to prepare heterogeneous catalysts [21, 22]. Such a heterogeneous catalyst system offers practical advantages in catalyst separation and potential recycling over its homogeneous counterpart $[23,24]$. Silica gel such as mesoporous silica MCM-41 and SBA-15 has been successfully used as inorganic supports for the immobilization of homogeneous catalysts [25-27]. However, despite having highly ordered mesopores, SBA-16 silica has been scarcely explored in this area. Herein, we described the synthesis of SBA-16 supported cinchona alkaloid ligand and tested it for the osmium catalyzed $\mathrm{AD}$ reaction of olefins to diols, a key reaction in organic synthesis.

\section{Experimental Details}

2.1. Preparation of the SBA-16 Silica. SBA-16 silica was synthesized at room temperature under acidic condition using Pluronic F127 $\left(\mathrm{EO}_{106} \mathrm{PO}_{70} \mathrm{EO}_{106}, M_{w}=12.6 \mathrm{~K}\right)$ as a structure-directing agent (SDA) [28]. The acidic solution was made by adding $1.5 \mathrm{~g}$ of deionized (DI) water to $120 \mathrm{~g}$ of 



SCHEME 1: Preparation of SBA-16-supported biscinchona alkaloid $\mathbf{1 .}$

$2 \mathrm{M} \mathrm{HCl}$ solution at room temperature. Subsequently, $8.5 \mathrm{~g}$ of tetraethoxysilane (TEOS) was added onto the solution and stirring continued for $20 \mathrm{~h}$. The reaction mixture was kept at $100^{\circ} \mathrm{C}$ for $48 \mathrm{~h}$. During this time the solid SBA-16 was produced under static conditions in a Teflon-lined vessel. The solid product was recovered and washed with DI water. Calcination was carried out slowly by increasing temperature from room temperature to $500^{\circ} \mathrm{C}$ in $8 \mathrm{~h}$ and heating at $500^{\circ} \mathrm{C}$ for another $6 \mathrm{~h}$.

2.2. Preparation of the 1,4-Bis(9-O-quininyl)phthalazine 3. $\mathrm{NaH}(2.24 \mathrm{mmol})$ at $0^{\circ} \mathrm{C}$ was slowly added to a stirred solution of 1,4-dichlorophthalazine $(0.5 \mathrm{mmol})$ and quinine 4 $(1.15 \mathrm{mmol})$ in THF $(8 \mathrm{~mL})$. The solution was stirred at $60^{\circ} \mathrm{C}$ for $2 \mathrm{~h}$ and then it was quenched at $0^{\circ} \mathrm{C}$ by careful addition of water. The mixture was extracted in ethyl acetate (EtOAc) and the solvent was removed under reduced pressure. The residue was purified by short column chromatography to separate 1,4bis(9-O-quininyl)phthalazine 3 and $82 \%$ yield was obtained.

\subsection{Preparation of the Triethoxysilanized 1,4-Bis(9-O-quin-} inyl)phthalazine 2. 1,4-Bis(9-O-quininyl)phthalazine 3 $(0.5 \mathrm{mmol})$ was added to a solution of (3-mercapto-propyl) triethoxysilane $(1.25 \mathrm{mmol})$ and $\alpha, \alpha^{\prime}$-azoisobutyronitrile (AIBN) $(0.10 \mathrm{mmol})$ in degassed chloroform $(10 \mathrm{~mL})$ under $\mathrm{N}_{2}$ atmosphere. The reaction mixture was refluxed for $30 \mathrm{~h}$ and concentrated under reduced pressure. The residue was purified by flash short column on silica gel to give compound 2 with $80 \%$ yield.
2.4. Immobilization of Biscinchona Alkaloid 2 onto SBA16 Silica 1. SBA-16 silica $(1.0 \mathrm{~g})$ was suspended in toluene and refluxed with compound 2 (145 mg, $0.124 \mathrm{mmol}$ ). After $12 \mathrm{~h}$, the powder was collected by filtration and washed with methanol and methylene chloride. After drying under vacuum at $70^{\circ} \mathrm{C}$, SBA-16-supported alkaloid 1 (1.077 g) was obtained. Elemental analysis and weight gain showed that $0.073 \mathrm{mmol}$ of 1,4 -bis(9-O-quininyl)phthalazine was anchored on $1.0 \mathrm{~g}$ of SBA-16-supported chiral Ligand $\mathbf{1}$.

\subsection{Characterization of SBA-16-Supported Chiral Ligand $\mathbf{1}$.} Powder X-ray diffractometry (Philips PW 1729) was used for the determination of crystalline structure using $\mathrm{CuK}$ radiation over $0.5^{\circ} \leq 2 \theta \leq 3$. The XRD sample of SBA-16 was analyzed at $30^{\circ} \mathrm{C}$. The diffractograms showed 3 peaks at $2 \theta \approx 0.74^{\circ}, 1.1^{\circ}$, and $1.4^{\circ}$ that corresponded to (110), (200), and (211) planes, respectively, in the cubic $\operatorname{Im} 3 m$ structure. The transmission electron microscopy (TEM) was performed with a FEI Tecnai $\mathrm{G}^{2}$ microscope operated at $200 \mathrm{kV}$. The TEM sample was prepared by placing a few drops of SBA-16 powder dispersed in acetone on a carbon grid and allowing it to dry for $5 \mathrm{~min}$ before TEM analysis. Large particles were crushed by submerging them in liquid nitrogen followed by mechanical grinding in a mortar prior to acetone dispersion. The nitrogen adsorption-desorption measurements were performed at $-196^{\circ} \mathrm{C}$ on a Micromeritics ASAP 2020 surface area and porosity analyzer. Approximately $0.5 \mathrm{~g}$ of SBA-16 was degassed at $300^{\circ} \mathrm{C}$ for $9 \mathrm{~h}$ before taking the measurement. The surface area determination was performed by the BrunauerEmmett-Teller (BET) method [29] over the relative pressure 
$\left(P / P_{0}\right)$ range of $0.05-0.2$. The pore-size distribution was determined using the Broekhoff-de Boer (BdB) method [30] applied to the adsorption branch. Finally, the total pore volume was calculated from the amount of adsorbed $\mathrm{N}_{2}$ at $P / P_{0}=0.99$, and the microporous volume was determined using the $t$-plot method.

2.6. Asymmetric Dihydroxylation of Olefin Using SBA-16Supported Chiral Ligand 1. A mixture of SBA-16-supported biscinchona alkaloid 1 ( $1 \mathrm{~mol} \%)$, potassium ferricyanide $(1.5 \mathrm{mmol})$, potassium carbonate $(1.5 \mathrm{mmol})$, and $\mathrm{OsO}_{4}$ $(1 \mathrm{~mol} \%, 0.5 \mathrm{M}$ in water) in tert-butyl alcohol-water $(6 \mathrm{~mL}$, $1: 1, \mathrm{v} / \mathrm{v})$ was stirred at room temperature for $30 \mathrm{~min}$. Olefin $(0.5 \mathrm{mmol})$ was added at once and stirred for $7 \sim 15 \mathrm{~h}$. The reaction mixture was diluted with water and $\mathrm{CH}_{2} \mathrm{Cl}_{2}$ and the immobilized Ligand 1 was separated by filtration. The crude product was purified by flash column chromatography, and the enantiomeric excess of the diol was determined by chiral gas chromatography (GC) analysis (Agilent HP Chiral-20B 30MX0.25MMX0.25UM GC Column).

\section{Results and Discussion}

To synthesize a SBA-16-supported biscinchona alkaloid 1, we started with quinine and 1,4-dichlorophthalazine following a route shown in Scheme 1.

Treatment of optically active quinine 4 with 1,4-dichlorophthalazine in the presence of excess $\mathrm{NaH}$ synthesized 4-bis(9-O-quininyl)phthalazine 3 with high yield (82\%). Radical reaction of dimeric quinine 3 with (3-mercaptopropyl)triethoxysilane in the presence of AIBN radical initiator provided compound 2 having a pendant triethoxysilane functional group. The desired immobilized biscinchona alkaloid SBA-16 1 (loading ratio: $0.073 \mathrm{mmol} / \mathrm{g}$ ) was readily obtained by condensation of 2 with surface silanols of SBA-16 support in refluxing toluene. The degree of functionalization was determined by elemental analysis and weight gain. As shown in Table 1, the surface area and pore diameter were decreased following the modification. The high resolution transmission electron microscopy (HRTEM) image of SBA16-supported Ligand $\mathbf{1}$ is shown in Figure 1. The 3D cubic structure and the pore arrays were conserved after the immobilization of 1,4-bis(9-O-quininyl)phthalazine onto SBA-16 silica and it was also confirmed by XRD (Figure 2).

The $\mathrm{AD}$ reaction of stilbene was performed in the presence of immobilized cinchona alkaloid $1(1 \mathrm{~mol} \%)$ and $\mathrm{OsO}_{4}(1 \mathrm{~mol} \%)$ at room temperature. Potassium carbonate and potassium ferricyanide were used as a secondary oxidant in tert-butyl alcohol-water mixture (1:1). The results are summarized in Table 2. Surprisingly, catalytic AD reactions of stilbene provided excellent enantioselectivities and high yields (entries 1 and 2). Osmium catalyst loading of $0.5 \mathrm{~mol} \%$ was sufficient to obtain outstanding enantioseletivity as well as high reactivity. Moreover, the SBA-16-supported alkaloid$\mathrm{OsO}_{4}$ complex could be reused for the $\mathrm{AD}$ reaction of stilbene without a significant loss of reactivity and enantioselectivity (entry 3 ). The catalyst was also highly effective to

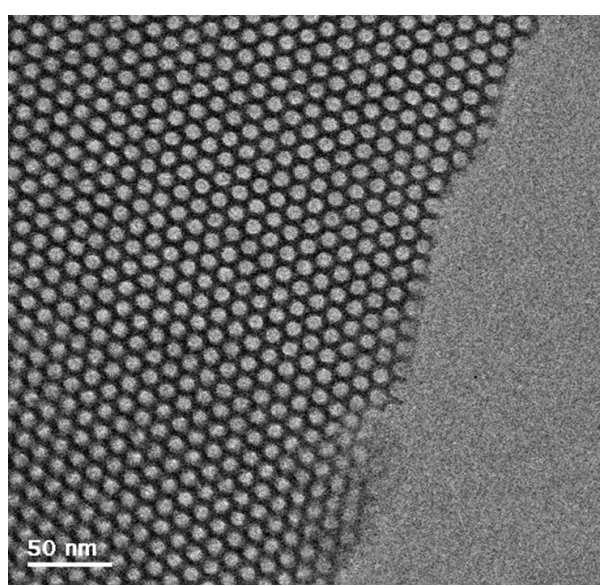

FIGURE 1: HRTEM image of SBA-16-supported Ligand $\mathbf{1}$

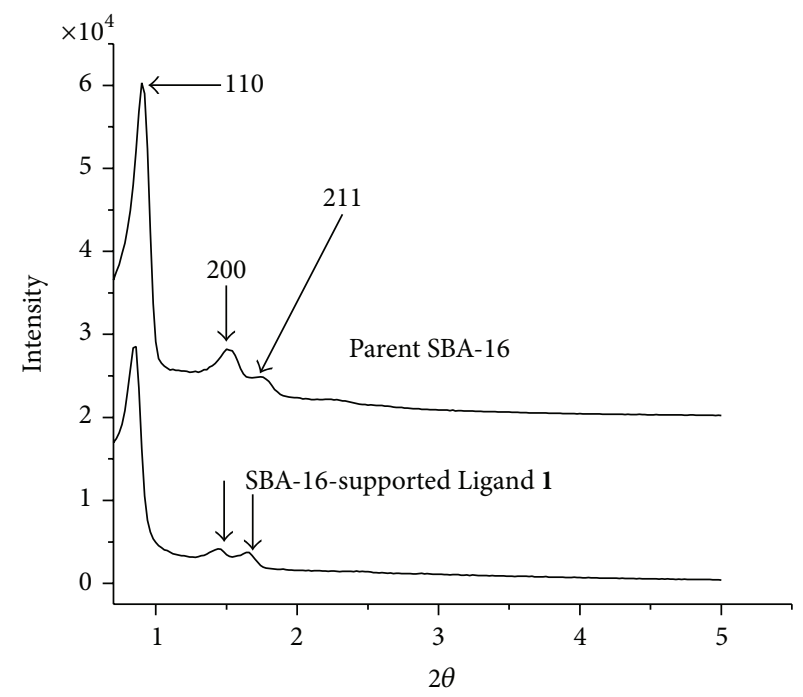

FIGURE 2: XRD pattern of SBA-16-supported Ligand $\mathbf{1}$.

AD of methylcinnamate, 1-phenyl-1-cyclohexene, and styrene (entries 4-6).

The SBA-16-supported Ligand 1 reported here showed somewhat higher reactivity and better asymmetric induction over amorphous silica-supported biscinchona alkaloid [25]. The improved outcome of the reaction seems to be attributed to the ordered array of chiral catalytic site on the nanopore surface of SBA-16 support. The ordered array leads to elegant site isolation which may result in enhanced enantioselectivity.

Romero et al. [31] reported the asymmetric dihydroxylation reaction of olefin using ionic liquid, which involves high cost and toxicity. The yield and enantioselectivity of the styrene were also very poor ( $87 \%$ yield, $62 \%$ ee) [32]. On the other hand, Junttila and Hormi [33] used methanesulfonamide as an accelerator of the asymmetric dihydroxylation reaction using potassium osmate (vi) and obtained $97 \%$ ee with low yield (70\%) of the diol product. It is noteworthy here that the alkaloid ligand complexes synthesized in this report produced excellent results in terms of both yield (93\%) and enantioselectivity (92-99\%). 
TABLE 1: Structural characteristics of SBA-16-supported Ligand 1.

\begin{tabular}{lcccc}
\hline Sample & Surface area & Pore diameter & Pore volume & Functional group \\
\hline SBA-16 & $820 \mathrm{~m}^{2} / \mathrm{g}$ & $5.13 \mathrm{~nm}$ & $0.73 \mathrm{~cm}^{3} / \mathrm{g}$ & - \\
$\mathbf{1}$ & $490 \mathrm{~m}^{2} / \mathrm{g}$ & $3.68 \mathrm{~nm}$ & $0.45 \mathrm{~cm}^{3} / \mathrm{g}$ & $0.073 \mathrm{mmol} / \mathrm{g}$ \\
\hline
\end{tabular}

TABLE 2: Heterogeneous AD of olefins using SBA-16-supported Ligand $\mathbf{1}^{\mathrm{a}}$.

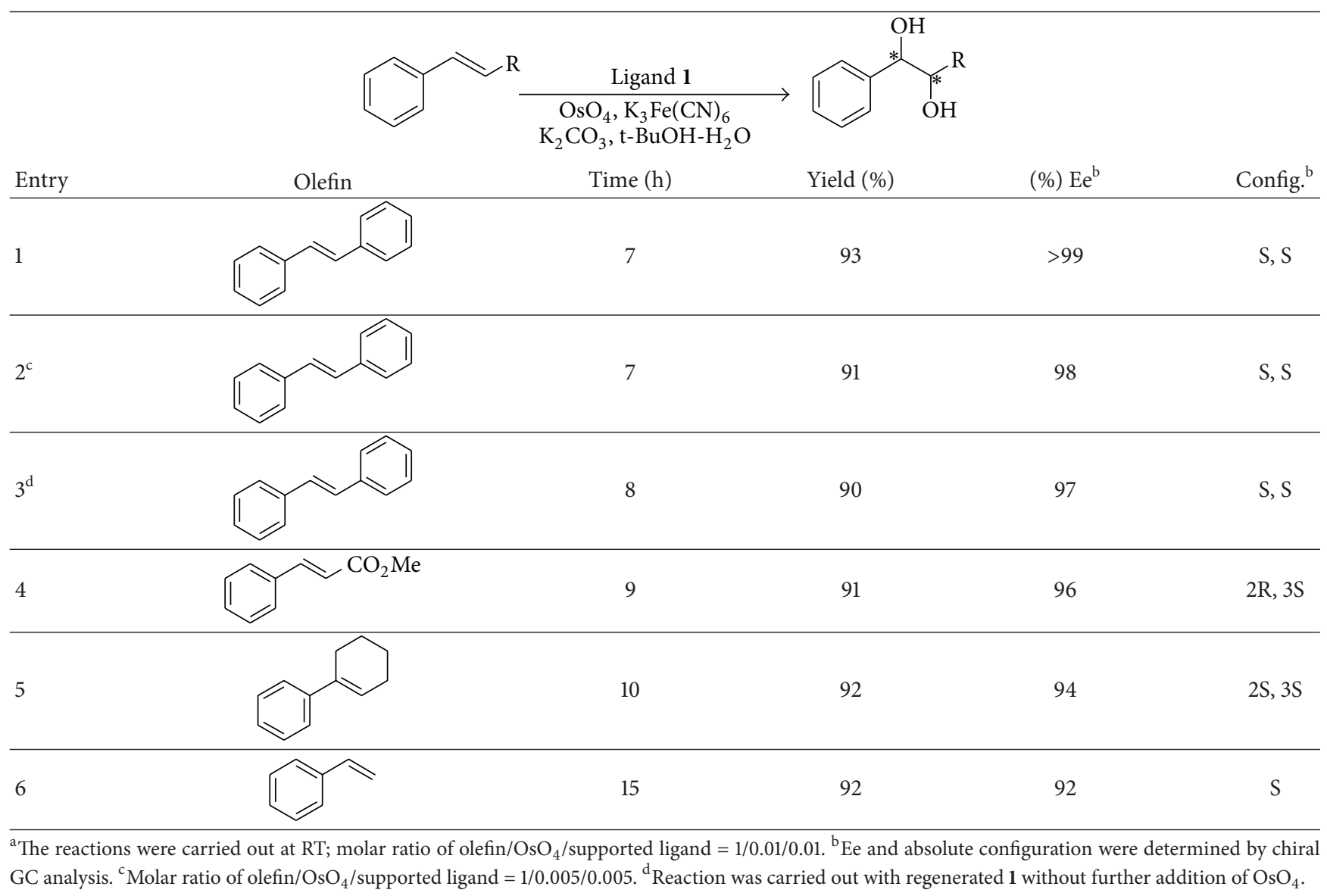

\section{Conclusion}

We successfully synthesized air and moisture stable SBA16-supported biscinchona alkaloid chiral ligand. Osmium tetraoxide readily formed a chiral complex with the SBA16-supported biscinchona alkaloid at room temperature. The synthesized SBA-16 supported Os-complex efficiently promoted the asymmetric dihydroxylation of olefin to corresponding diols with 92-99\% enantioselectivity and 93\% yield, demonstrating SBA-16 silica as an excellent support material for the heterogeneous chiral ligand.

\section{Conflict of Interests}

The authors declare that they have no conflict of interests regarding the publication of this paper.

\section{Acknowledgment}

This work was supported by University of Malaya fund no. RP005A-13AET to M. E. Ali.

\section{References}

[1] A. Corma, "From microporous to mesoporous molecular sieve materials and their use in catalysis," Chemical Reviews, vol. 97, no. 6, pp. 2373-2420, 1997.

[2] U. Ciesla and F. Schüth, "Ordered mesoporous materials," Microporous and Mesoporous Materials, vol. 27, no. 2-3, pp. 131149, 1999.

[3] A. Taguchi and F. Schüth, "Ordered mesoporous materials in catalysis," Microporous and Mesoporous Materials, vol. 77, no. 1, pp. 1-45, 2005. 
[4] Y. K. Hwang, J.-S. Chang, Y.-U. Kwon, and S.-E. Park, "Microwave synthesis of cubic mesoporous silica SBA-16," Microporous and Mesoporous Materials, vol. 68, no. 1-3, pp. 21-27, 2004.

[5] R. A. Fernandes and A. K. Chowdhury, "Stereoselective total synthesis of (+)-nephrosteranic acid and (+)-roccellaric acid through asymmetric dihydroxylation and Johnson-Claisen rearrangement," European Journal of Organic Chemistry, vol. 2011, no. 6, pp. 1106-1112, 2011.

[6] D. Yamashita, Y. Murata, N. Hikage, K.-I. Takao, A. Nakazaki, and S. Kobayashi, "Total synthesis of (-)-norzoanthamine," Angewandte Chemie-International Edition, vol. 48, no. 8, pp. 1404-1406, 2009.

[7] P. Gao, Z. Tong, H. Hu et al., "Synthesis of (+)-9a-epi-stemoamide via DBU-catalyzed michael addition of nitroalkane," Synlett, no. 13, pp. 2188-2190, 2009.

[8] C. Yu, B. Tian, J. Fan, G. D. Stucky, and D. Zhao, "Nonionic block copolymer synthesis of large-pore cubic mesoporous single crystals by use of inorganic salts," Journal of the American Chemical Society, vol. 124, no. 17, pp. 4556-4557, 2002.

[9] Y. Sakamoto, M. Kaneda, O. Terasaki et al., "Direct imaging of the pores and cages of three-dimensional mesoporous materials," Nature, vol. 408, no. 6811, pp. 449-453, 2000.

[10] N. Md. Alam, S. M. Sarkar, and R. Md. Miah, "Heterogeneous Heck reaction catalysed by silica gel-supported 1,2diaminocyclohexane-Pd complex," Reaction Kinetics and Catalysis Letters, vol. 98, no. 2, pp. 383-389, 2009.

[11] E. N. Jacobsen, A. Pfaltz, and H. Yamamoto, in Comprehensive Asymmetric Catalysis II, Springer, Berlin, Germany, 1999.

[12] D. J. Smaltz and A. G. Myers, "Scalable synthesis of enantiomerically pure syn-2,3-dihydroxybutyrate by sharpless asymmetric dihydroxylation of $p$-phenylbenzyl crotonate," The Journal of Organic Chemistry, vol. 76, no. 20, pp. 8554-8559, 2011.

[13] J. Peed, I. R. Davies, L. R. Peacock, J. E. Taylor, G. K. Köhn, and S. D. Bull, "Dihydroxylation-based approach for the asymmetric syntheses of hydroxy- $\gamma$-butyrolactones," The Journal of Organic Chemistry, vol. 77, no. 1, pp. 543-555, 2012.

[14] M. X. Zhao, H. L. Bi, H. Zhou, H. Yang, and M. Shi, "Cinchona alkaloid squaramide catalyzed enantioselective hydrazination/cyclization cascade reaction of $\alpha$-isocyanoacetates and azodicarboxylates: synthesis of optically active 1,2,4triazolines," The Journal of Organic Chemistry, vol. 78, p. 9377, 2013.

[15] H. C. Kolb, M. S. VanNieuwenhze, and K. B. Sharpless, "Catalytic asymmetric dihydroxylation," Chemical Reviews, vol. 94, no. 8, pp. 2483-2547, 1994.

[16] H. Salim and O. Piva, "A short access to 3-hydroxy-4hydroxymethyltetrahydrofurans: application to the total synthesis of amphiasterin B4," The Journal of Organic Chemistry, vol. 74, no. 5, pp. 2257-2260, 2009.

[17] G.-B. Ren and Y. Wu, "Enantioselective total synthesis and correction of the absolute configuration of megislactone," Tetrahedron, vol. 64, no. 19, pp. 4408-4415, 2008.

[18] X. Huo, X. Ren, Y. Xu, X. Li, X. She, and X. Pan, "Enantioselective total synthesis of hydramicromelin B," Tetrahedron Asymmetry, vol. 19, no. 3, pp. 343-347, 2008.

[19] L. L. Lazarusa and R. L. Brutchey, "Heterogeneous fullerene-supported osmium tetroxide catalyst for the cis-dihydroxylation of olefins," Dalton Transactions, vol. 39, pp. 78887890, 2010.
[20] R. Cano, J. M. Pérez, and D. J. Ramón, “Osmium impregnated on magnetite as a heterogeneous catalyst for the syndihydroxylation of alkenes," Applied Catalysis A: General, vol. 470, pp. 177-182, 2004.

[21] S. M. Sarkar, N. Md. Alam, and R. Md. Miah, "Highly efficient silica gel-supported 1,2-diaminocyclohexane-Pd catalyst for Suzuki-Miyaura and Sonogashira coupling reactions," Reaction Kinetics and Catalysis Letters, vol. 96, no. 1, pp. 175-183, 2009.

[22] N. Md. Alam and S. M. Sarkar, "Mesoporous MCM-41 supported N-heterocyclic carbene-Pd(II) complex for Suzuki coupling reaction," Reaction Kinetics, Mechanisms, and Catalysis, vol. 103, no. 2, pp. 493-500, 2011.

[23] M. S. Sarkar, H. Qiu, and M.-J. Jin, "Encapsulation of Pd complex in ionic liquid on highly ordered mesoporous silica MCM-41," Journal of Nanoscience and Nanotechnology, vol. 7, no. 11, pp. 3880-3883, 2007.

[24] H. Qiu, S. M. Sarkar, H. Do. Lee, and M. J. Jin, "Highly effective silica gel-supported $N$-heterocyclic carbene-Pd catalyst for Suzuki-Miyaura coupling reaction," Green Chemistry, vol. 10, pp. 37-40, 2008.

[25] C. E. Song, J. W. Yang, and H.-J. Ha, "Silica gel supported biscinchona alkaloid: a highly efficient chiral ligand for heterogeneous asymmetric dihydroxylation of olefins," Tetrahedron Asymmetry, vol. 8, no. 6, pp. 841-844, 1997.

[26] S. H. Kim and M. J. Jin, "Asymmetric dihydroxylation catalyzed by MCM-41 silica-supported bis-cinchona alkaloid," Studies in Surface Science and Catalysis, vol. 146, pp. 677-680, 2003.

[27] H. M. Lee, S.-W. Kim, T. Hyeon, and B. M. Kim, "Asymmetric dihydroxylation using heterogenized cinchona alkaloid ligands on mesoporous silica," Tetrahedron Asymmetry, vol. 12, no. 11, pp. 1537-1541, 2001.

[28] D. Zhao, Q. Huo, J. Feng, B. F. Chmelka, and G. D. Stucky, "Nonionic triblock and star diblock copolymer and oligomeric sufactant syntheses of highly ordered, hydrothermally stable, mesoporous silica structures," Journal of the American Chemical Society, vol. 120, no. 24, pp. 6024-6036, 1998.

[29] S. Brunauer, P. H. Emmett, and E. Teller, "Adsorption of gases in multimolecular layers," Journal of the American Chemical Society, vol. 60, no. 2, pp. 309-319, 1938.

[30] W. W. Lukens Jr., P. Schmidt-Winkel, D. Zhao, J. Feng, and G. D. Stucky, "Evaluating pore sizes in mesoporous materials: a simplified standard adsorption method and a simplified Broekhoff-de Boer method," Langmuir, vol. 15, no. 16, pp. 54035409, 1999.

[31] A. Romero, A. Santos, J. Tojo, and A. Rodríguez, "Toxicity and biodegradability of imidazolium ionic liquids," Journal of Hazardous Materials, vol. 151, no. 1, pp. 268-273, 2008.

[32] L. C. Branco and C. A. M. Afonso, "Ionic liquids as a convenient new medium for the catalytic asymmetric dihydroxylation of olefins using a recoverable and reusable osmium/ligand," The Journal of Organic Chemistry, vol. 69, no. 13, pp. 4381-4389, 2004.

[33] M. H. Junttila and O. O. E. Hormi, "Methanesulfonamide: a cosolvent and a general acid catalyst in sharpless asymmetric dihydroxylations," Journal of Organic Chemistry, vol. 74, no. 8, pp. 3038-3047, 2009. 

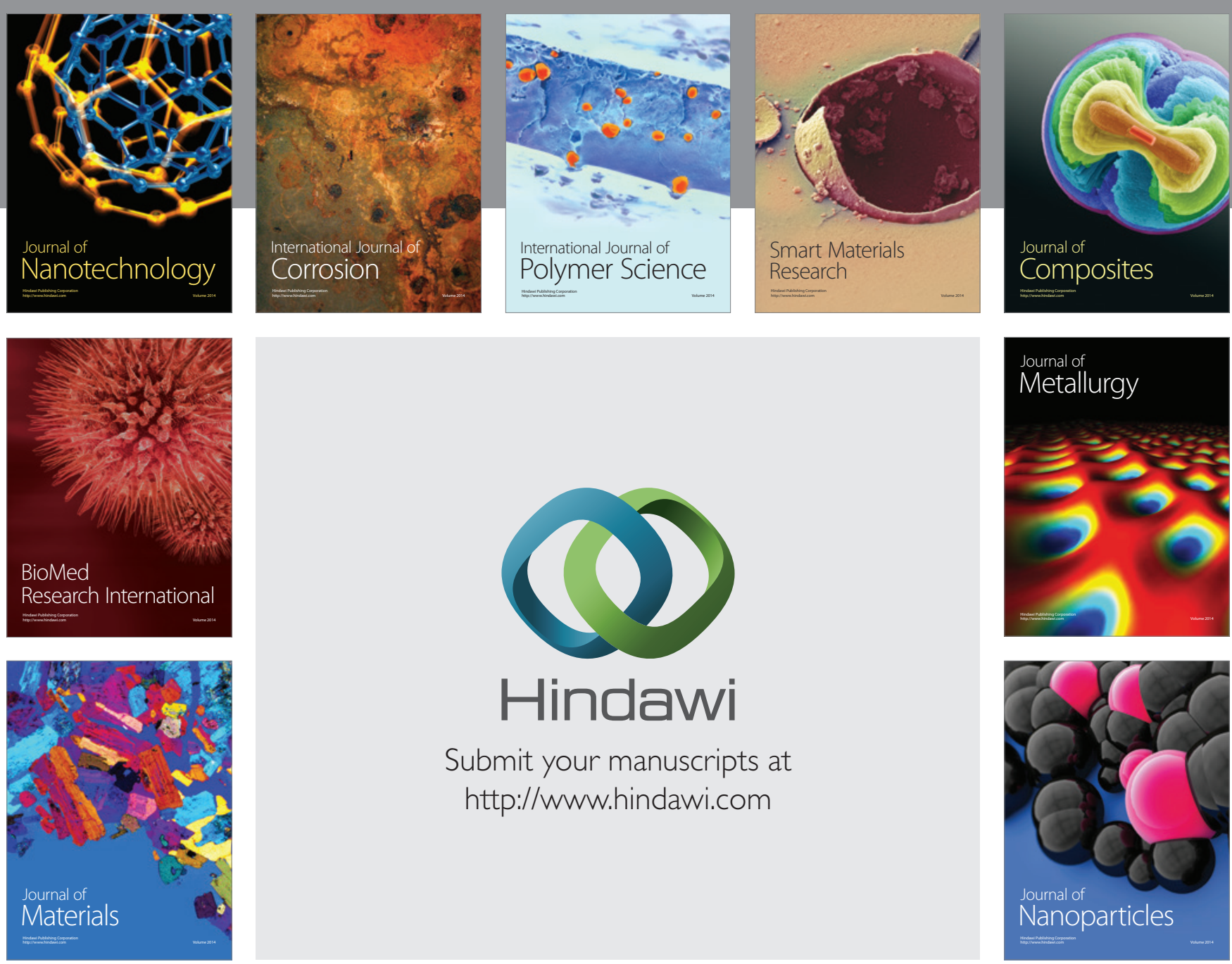

Submit your manuscripts at http://www.hindawi.com
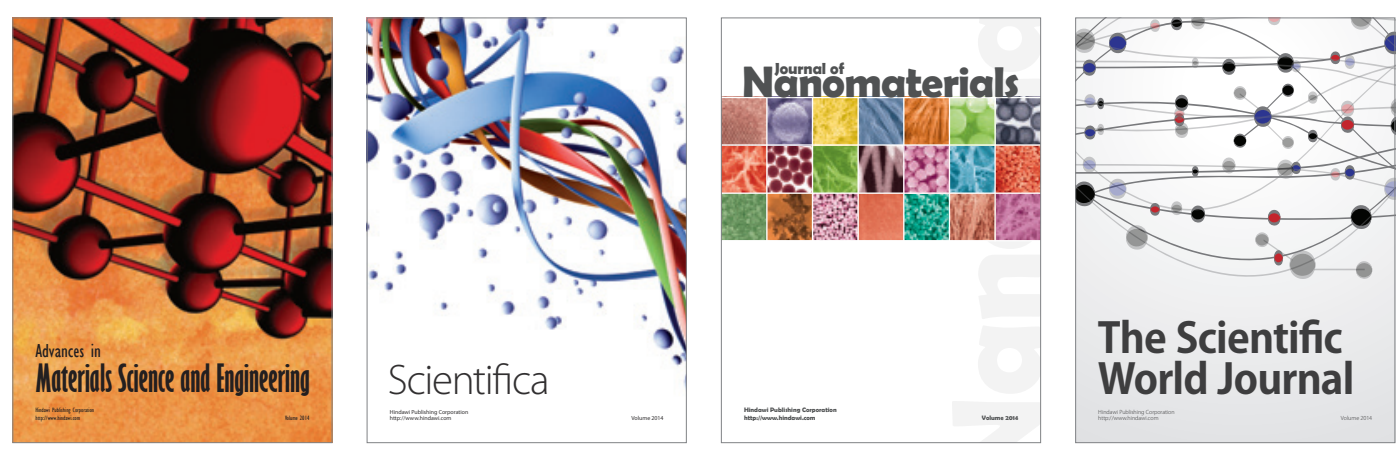

\section{The Scientific World Journal}
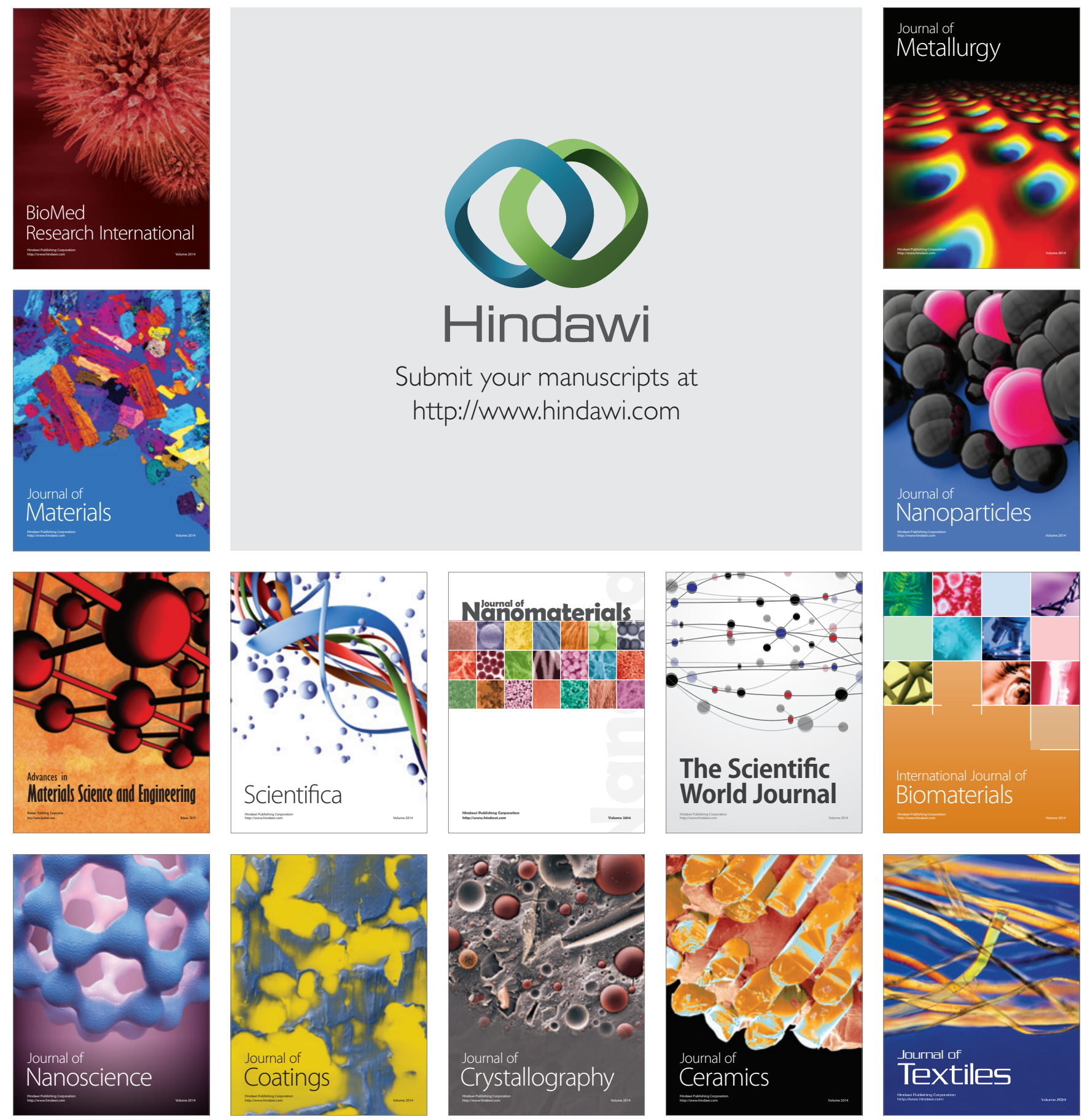